\title{
Creating Belonging and Community in a Makerspace, Before and During COVID-19
}

Tiffany Carlson, University of Minnesota, Twin Cities

Erik Halaas, University of Minnesota, Twin Cities

Carolyn Bishoff, University of Minnesota, Twin Cities

\section{ABSTRACT \\ The Breakerspace at the University of Minnesota-Twin Cities is a vibrant library makerspace open to all majors and skill levels and located right in the heart of campus. The design of the space and all of our decisions have been animated by the goal to empower and inspire students through access to creative materials, equipment, and programming. When our buildings closed during the COVID-19 pandemic, the Breakerspace closed as well. In this article, we discuss how we adapted our work in the makerspace to a socially distanced and remote environment, with an extra emphasis on virtual community.}

\section{KEYWORDS}

Makerspace, pandemic, virtual community

\section{SUGGESTED CITATION}

Carlson, T., Halaas, E., \& Bishoff, C. (2022). Creating belonging and community in a makerspace, before and during COVID-19. Journal of New Librarianship, 7(1), 17-26. https://doi.org/10.33011/newlibs/11/3

This is an Open Access article distributed under the terms of the Creative Commons Attribution 4.0 International License (http://creativecommons.org/licenses/by/4.0), which permits unrestricted use, distribution, and reproduction in any medium, provided the original work is properly cited. 
The Breakerspace at the University of Minnesota-Twin Cities is an open, vibrant library makerspace located in Walter Library's Toaster Innovation Hub right in the heart of campus. Students entering the space are met with shelves of craft supplies, paper, and vinyl; a sewing machine; button makers; a handful of $3 \mathrm{D}$ printers; two Cricut vinyl cutters; and lots of workspace for students to engage in the glorious, messy business of creativity. The Breakerspace was meant to complement existing fabrication spaces on campus. Most other fabrication spaces had been around much longer and had more advanced equipment, but often had limitations on who could use it and why. Several were available only to students enrolled in certain majorsusually for classwork only-and many of them charged fees.

The Breakerspace began as a pilot space. It opened in 2017 with just a handful of equipment and furniture salvaged from the university's reuse center. The two primary principles were that it would be free and open to all. To start, we opened the space with low-barrier creative resources that students could use at no cost. We wanted any student who encountered the space to feel empowered to use the supplies, explore the equipment, and create what they wanted without fear of failure, being policed, or feeling like they're not using the space for the right reasons. We wanted students of all skill levels and abilities to feel a sense of belonging when they walked into the space. Students are the experts in their interests and experiences, so we offered lots of low-barrier and anonymous ways for them to tell us what was working, what wasn't, and what they wanted.

The idea for the Toaster Innovation Hub was developed in 2019 to bring together the resources and people who support undergraduate innovation and entrepreneurship. Faculty and staff in the Gary S. Holmes Center for Entrepreneurship and the University of Minnesota Libraries wanted to bring together all the programs and resources available to undergraduates interested in entrepreneurship from around campus and the greater Minneapolis-St. Paul area. After hundreds of staff hours of analysis, storing, and shifting, about 7,0oo square feet of the library was cleared of collections and shelving. A bright and open space took shape in 2019, with a spot for the Breakerspace.

The Toaster's opening week was in February 2020. We had just relocated the Breakerspace from the temporary pilot space to its new home. Then in March 2020 the University of Minnesota-Twin Cities closed its buildings and everyone went home. Unfortunately for us, the Breakerspace was designed around peer learning and in-person community building. When COVID became our reality, we had no safe ways for people to share space and supplies as they could before the pandemic. The soft supplies, like yarn and fabric, and opportunities for close connection that made our space so welcoming and warm were suddenly hot spots for possible virus transmission. It wasn't feasible to stay open anymore, so we closed out of concern for the safety of our users. 
The Breakerspace was founded to help address some of the inequities on campus with regards to access to creative materials and spaces. Up to that point we had grown and evolved by taking an interest in our users' work, their backgrounds, and their needs. Our users were the driver and the lifeblood of the space. Without them it was hard to know what to do next.

\section{Free and Open to All}

We designed the Breakerspace primarily for students with limited access to creative resources and equipment. Our vision was that student interests would shape the direction of the space, and we knew we had to take an active role if we wanted to achieve this.

At first, we invited students to send us an email or leave a note on a whiteboard, but we discovered that the most popular option for students to communicate their needs to us was with sticky notes. So, we put a piece of paper up, prompted with "What would you like to see in the Breakerspace?" and provided markers and sticky notes for students to anonymously share their requests (see Figure 1). We responded to these requests with sticky notes of our own, starting an anonymous dialogue in bright colors right there in the space. Rather than silently fulfilling requests, we "wrote back" to show other students that there was someone reading the comments and valuing their input and ideas. To this day, we use this method to gain insights into student ideas and requests for our space.

\section{Figure 1}

\section{Suggestion Board}

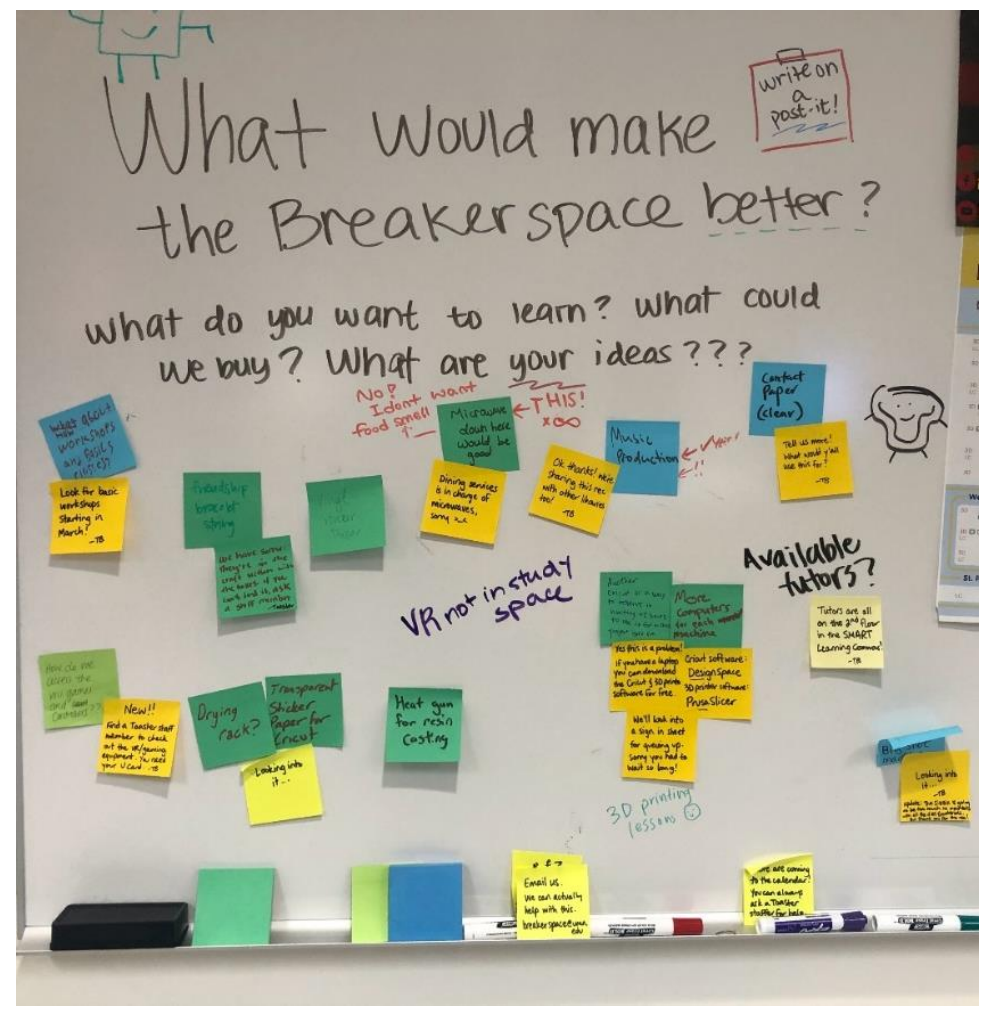


Students often express surprise or puzzlement when they encounter the Breakerspace. It is adjacent to spaces that host events and group study areas. It wasn't unusual for someone to walk in looking for a place to sit and study, wander toward the shelves of craft supplies and $3 \mathrm{D}$ printers, and wonder aloud, "Is it OK if I'm here?" Unlike other spaces that students had to use for classes and projects, anyone who used the Breakerspace was doing so voluntarily. And despite our best efforts, we knew that the idea of makerspaces carries baggage that might even originate in primary school: Different folks have different ideas of the kind of projects that are allowed as well as who is or isn't inherently welcome (Noonoo, 2018).

We strike a balance between actively inviting people into the space and staying out of their way. We host dozens of workshops a semester, set up simple five-minute make-and-take projects at the entrance, and keep a clean, organized, and colorful environment that emphasizes workspace rather than technology. This way we guide them in, give them the tools to gain confidence and comfort, and then step back. We have watched our users quietly and anonymously build the space into a vibrant, creative place that is centered around their interests. The sticky notes mentioned earlier help a lot with this, as well as the friendships and communities that naturally developed when peer-to-peer learning began to take place as more users engaged with the space.

\section{Markers of Belonging}

Dr. Zeynep Tufekci (2014) talks about the arbitrary but powerful ways that in-groups and out-groups are defined and fortified. In her blog post about "bro culture" in Silicon Valley, she talks about how a sense of community can be created from shared "markers of belonging" (2014, para. 12). These markers can seem benign, like wearing a hoodie at work or writing code in arcane programming languages.

We did not want any arbitrary or exclusive "markers of belonging" to develop in the Breakerspace. We knew it could happen because we saw evidence in other spaces. Visiting other campus makerspaces, we noted that students appeared they belonged when they moved effortlessly through the workshop, used equipment independently and with ease, and had oneon-one relationships with the staff. As visitors to these spaces, we often felt acutely aware of our "outsider" status.

Our response was to create lots of pathways into the space. We developed an array of introductory workshops. They were designed to help folks gain comfort and familiarity with the space and equipment. The workshops taught the basics of $3 \mathrm{D}$ printing, sticker making, using the sewing machine, and virtual reality. They required no previous experience and did not have to be taken in order. Over time, students and staff came up with their own ideas: avocado seed carving, bullet journaling, miniature painting, cross stitching, and zine making. Seeding the space with different activities was important to us because we wanted to challenge assumptions 
about "acceptable" uses of the Breakerspace. We embraced activities that welcomed and encouraged beginners and highlighted our users' passions.

Another unintentional "marker of belonging" we noted in other spaces was the ability to navigate unlabeled tool carts, leave unfinished projects in common workspaces, and the knowledge of what supplies were free or scrap and what was not. To put all our users on an equal playing field, we painstakingly labeled everything, created instructions for every piece of equipment, and made a habit of tidying and resetting the space daily. We used signs sparingly (knowing that few people stop to read them) and made sure that our signs were descriptive and friendly. For example, instead of a sign demanding "Clean up after yourself!" we had the location of cleaning supplies clearly marked with a little note, "Thank you for helping us keep the Breakerspace clean!" It is subtle but conveys a message of cooperation and gratitude. It asks all users to be part of the "in-group" who care for the space.

Finally, we designed the space to be accommodating to a wide spectrum of bodies, disabilities, and social identities. Accessibility is more than compliance. It communicates who belongs in the space and who is excluded. We made it our business to apply accessibility guidelines consistently and compassionately in the design of our space and staff training, and choice of furniture, equipment, and tools (AccessEngineering, 2015). This also meant changing the way our staff think about our role in the space. Instead of presuming that student users are out to damage our equipment or trash our space (a mindset in which white supremacy can take root and flourish) we train ourselves and our student staff to trust our users and treat them as partners and even teachers. We enforce our Library Use Policy, but we do not "[presume] an adversarial relationship" between our users and our staff (Moro, 2020, para. 2). When our users make mistakes (even mistakes that damage our equipment!) we approach the situation with curiosity and compassion. And finally, we make space to reflect on how we can improve our own processes so those mistakes might not happen in the future.

The Toaster Innovation Hub as a whole had similar challenges to the Breakerspace. The idea of entrepreneurship, like makerspaces, can come with baggage, and the project's relationship to the School of Business could draw some folks in and push others away. Putting the Toaster Innovation Hub in a library was one way of communicating that students do not have to be business majors or have prior experience to participate in innovation and entrepreneurship programs. We were also intentional about hiring Toaster student staff who had a wide variety of experiences with makerspaces and entrepreneurship, and who represented a variety of backgrounds, majors, and interests. We provided thoughtful training for our staff that included readings and reflection. As they became familiar with the creative tools and mindset of the space, they began brainstorming ways to reach out to student groups, offer workshops in their own areas of interest, and learn more advanced skills to broaden their own horizons. 
It was hard work, but slowly the Breakerspace became what we really hoped it would become: a bustling place where people could fully own their interests, identities, and creativity. The anecdotes and observations piled up: students with a service animals using the craft supplies, another student with their baby in a stroller laminating some cards for class, a queer sewing meetup, workshop after workshop with full registrations.

\section{The New Normal}

In March 2020, little was known about COVID-19. As other staff in the library worked to restore services and transition to a remote environment, the Toaster/Breakerspace team made the decision to close our space for the safety of our users. Before the pandemic our goal was to foster collaborative learning, hands-on activities, co-learning, and a shared space. Now those activities could potentially put our users at risk. This left us with a major conundrum on our hands: How do we continue to build community, create an inclusive space, and share knowledge of these maker skills without the ability to physically gather and use the materials?

There was not much we could do while the university buildings were closed to the public. We all lived in a bubble of uncertainty, especially during the spring of 2020. Staff attempted online workshops, but attendance was dismal. We tried to connect to our full-time and student staff over social media, but people were focused on adjusting to their new normal. Nothing was working.

So we took a step back. We adjusted to what life looked like during a global pandemic. The semester was chaotic, with lesson plans changing left and right. We acknowledged that the Breakerspace was not a priority for most people, even our most dedicated users. We decided to take this opportunity to really think hard and brainstorm about how to reach students when we would return in the Fall 2020 semester, either in person or virtually.

When the doors to the libraries reopened to university users in Fall 2020, large gatherings were still discouraged. Classes were mostly online and most of our staff continued to work from home. We had to create new norms. In the Toaster Innovation Hub, and the Breakerspace by extension, this worked to our advantage. The Breakerspace had moved out of our temporary pilot space and into the Toaster a mere three weeks before the shutdown. We had barely unpacked or started spring programming. We had our values, mindset, and a strong foundation based on creating pathways into the space, but we had no norms to speak of!

We began the work of creating our own norms based on belonging and connection. We wanted to emphasize to university staff and students that, even in the new normal of social distancing, mask wearing, remote learning, and work from home, we could still have community and connection over creative projects. Instead of leveraging the physical space to encourage creativity and community, our staff shifted our purpose during this time to provide virtual spaces where folks could connect safely. 
We offered a focused selection of online workshops. These were activities and skills that folks could easily do from home, like bullet journaling, podcasting, hand lettering, and calligraphy. As in the past, we relied on the passions of our staff to determine what workshops to offer. The pandemic was a time when many people were cultivating their passions, and these workshops exploded in popularity. The student staff created take-home kits, available for nocontact pickup in the space, to be used in conjunction with an online workshop via Zoom (see Figure 2).

\section{Figure 2}

\section{Workshop Take-Home Kits}

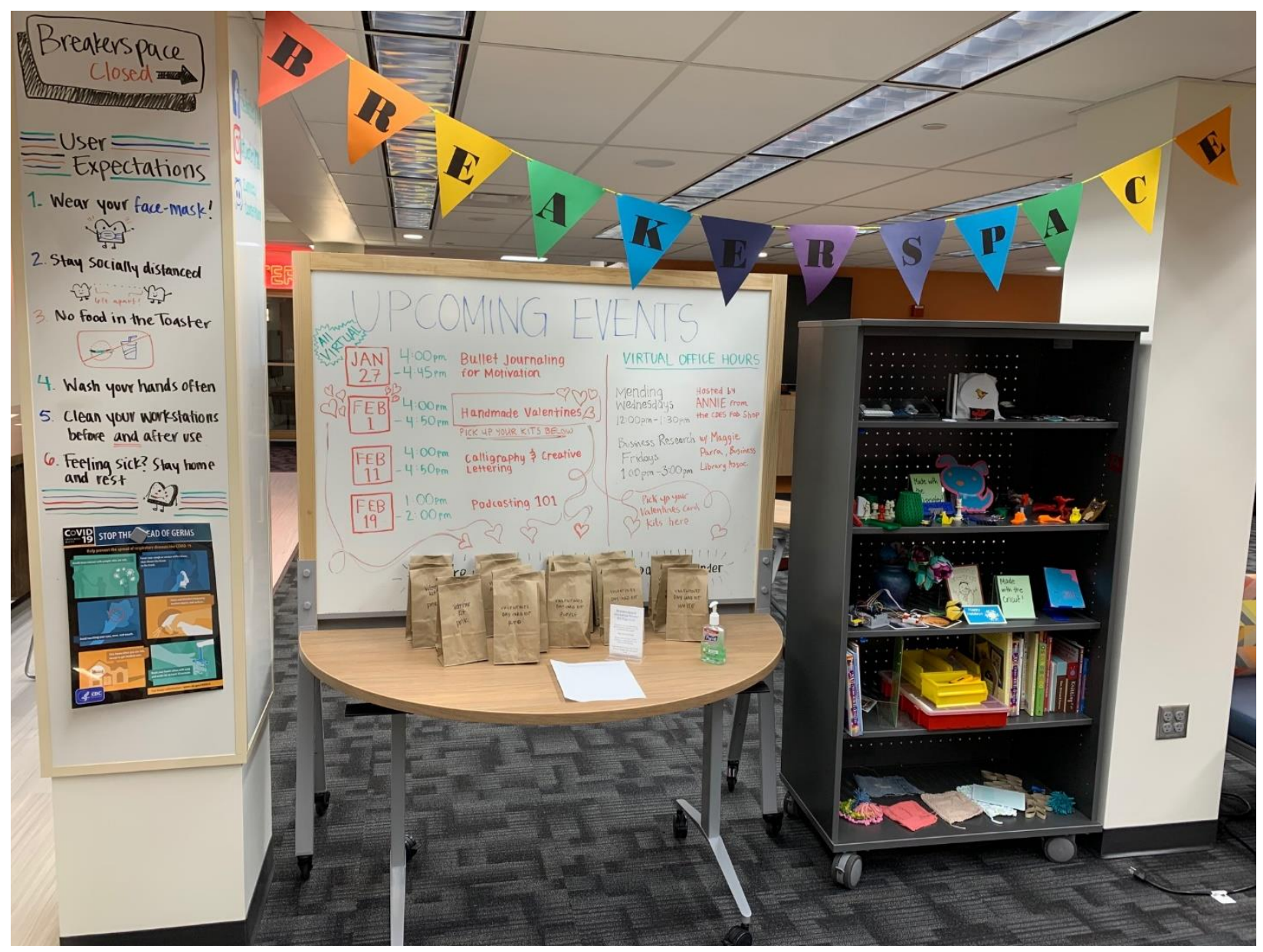

One of our Toaster students launched a Discord network where students could connect to staff and each other to discuss project ideas, share opportunities, and join calls and chats to learn more about the physical space while still safely at home. Discord is a group chat platform made up of communities called "servers." Originally built for gamers, it is now host to a vast number of online communities. The Toaster Discord provided an opportunity for students and other staff to feel connected back to the space. One channel was for sharing drawings that users 
made on the whiteboards. Another was for sharing photos of Breakerspace projects (see Figure 3). A voice channel was the meeting place for "Toaster Tip Tuesdays," a weekly lunchtime event that covered everything from $3 \mathrm{D}$ printing to mending. Folks could keep in touch while still quarantined to their rooms.

\section{Figure 3}

\section{Toaster Discord Network Post}

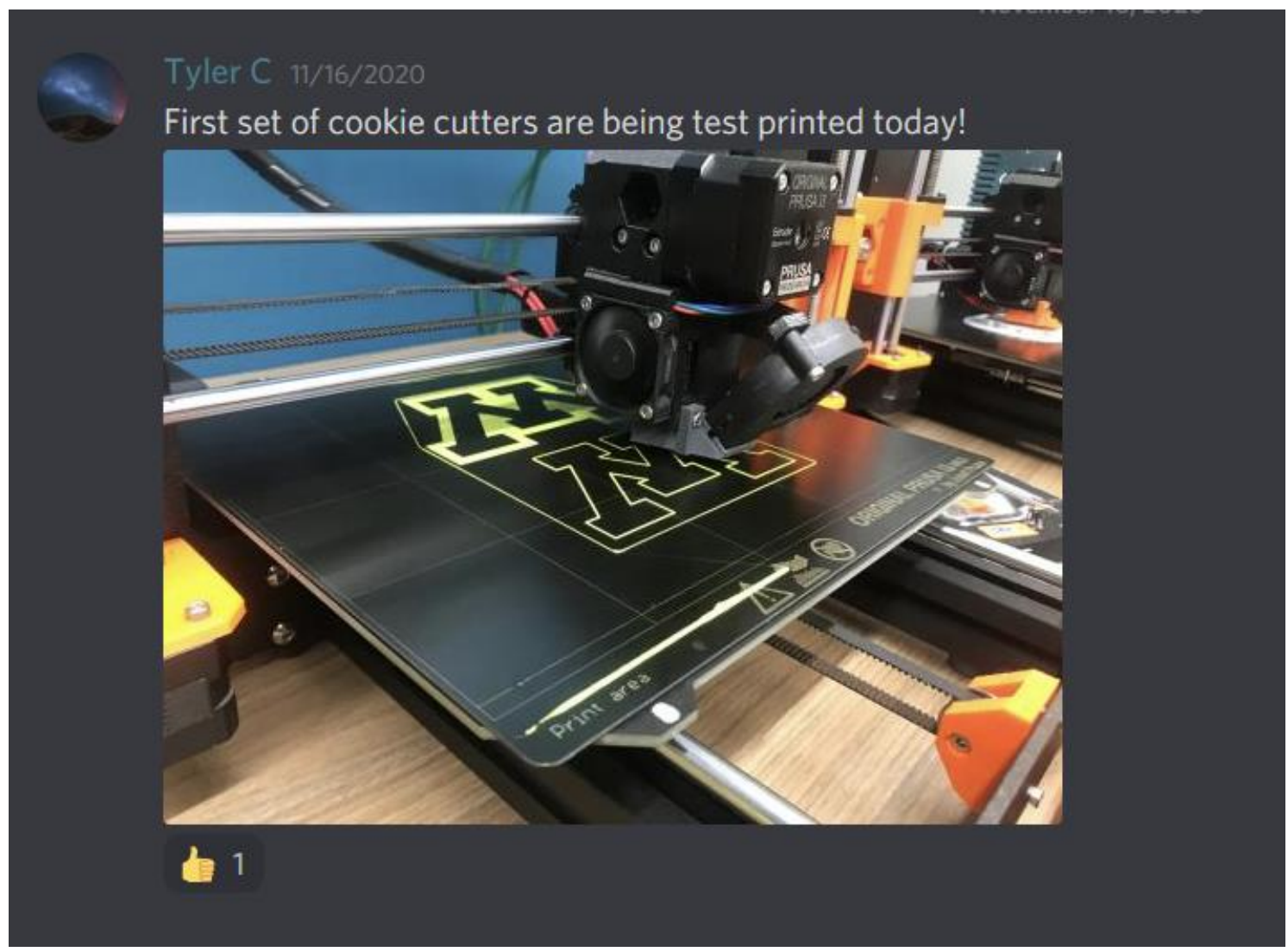

In a world of constant Zoom meetings and the very real onset of Zoom fatigue, why offer more events online? To us, it went beyond the screen and fit right in with the previous work we had done in the Breakerspace. We offered easy, low-barrier activities that students could do for free during one of the most collectively difficult and stressful times any of us had experienced. We felt no pressure to make sure our events were tied to academics because providing a space for creativity regardless of a student's major or connection to a class was how we had operated since the beginning. We were happy we could provide a place to gather, learn a skill, and have fun while doing it. It offered balance and reminded folks of the comfortable "old" normal while remaining safe in our "new" normal.

Will we continue online workshops, supply pickups, and a Discord channel when we can all safely share air again? We have so far. Virtual events and online meetups have some serious 
advantages to in-person workshops. Camera close-ups, good sound and captioning, and much higher registration limits mean more people can participate. We used to struggle with sound amplification in our busy, noisy space, which was tough for folks who were hard of hearing or had sensory needs.

We have been overjoyed to slowly welcome users back into the space after so many of us have been impacted by the spread of this terrible virus. But we also learned so much during this time: ways to make our programming and spaces even more inclusive and useful, what a successful online makerspace event looks like, and how to share our users' creativity and the fun of the space more widely. 


\section{References}

AccessEngineering. (2015). Making a makerspace? Guidelines for accessibility and Universal Design. University of Washington College of Engineering and DO-IT (Disabilities, Opportunities, Internetworking and Technology).

https://www.washington.edu/doit/making-makerspace-guidelines-accessibility-anduniversal-design

Moro, J. (2020, February 13). Against cop shit. JeffreyMoro.com. https://jeffreymoro.com/blog/2020-02-13-against-cop-shit/

Noonoo, S. (2018, June 14). Maker culture has a 'deeply unsettling' gender problem. EdSurge. https://www.edsurge.com/news/2018-06-14-maker-culture-has-a-deeply-unsettlinggender-problem

Tufekci, Z. (2014, March 18). No, Nate, brogrammers may not be macho, but that's not all there is to it. The Message. https://medium.com/message/no-nate-brogrammers-may-not-bemacho-but-thats-not-all-there-is-to-it-2fife $84 \mathrm{c} 5 \mathrm{cgb}$ 